\title{
Methimazole induced hepatotoxicity: A rare adverse reaction
}

\author{
Kevin C. Kohm*1, Lauren Pioppo ${ }^{2}$, Jack Xü ${ }^{2}$, Preston Keiffer ${ }^{1}$, Eric Pagan ${ }^{2}$, Jonathan Stoll ${ }^{2}$, Matthew Danish ${ }^{2}$, \\ Christine Fanning ${ }^{3}$, Matthew Sandel ${ }^{3}$ \\ ${ }^{1}$ Rutgers Robert Wood Johnson Medical School, New Brunswick, United States \\ ${ }^{2}$ Department of Medicine, Rutgers Robert Wood Johnson Medical School, New Brunswick, United States \\ ${ }^{3}$ Penn Medicine Princeton Health, Plainsboro, United States
}

Received: April 11, 2019

Accepted: May 26, 2019

Online Published: June 19, 2019

DOI: $10.5430 /$ crim.v6n3p1

URL: https://doi.org/10.5430/crim.v6n3p1

\begin{abstract}
Methimazole (MMI) is a commonly used medication in the treatment of hyperthyroidism. The side effect profile is extensive and includes the rare but serious side effect of drug associated liver injury. We report the case of a 51-year-old female who presented with painless jaundice several weeks after initiating MMI therapy for treatment of hyperthyroidism complicated by Graves' orbitopathy. Liver function tests on presentation showed alanine aminotransferase (ALT) 1366 IU/L, aspartate aminotransferase (AST) $853 \mathrm{IU} / \mathrm{L}$, total bilirubin $26.2 \mathrm{mg} / \mathrm{dl}$, alkaline phosphatase $954 \mathrm{IU} / \mathrm{L}$. Workup of structural, infectious, and autoimmune causes of hepatic injury was negative. The patient was therefore found to have MMI associated liver injury. MMI was discontinued and the patient was started on ursodiol, resulting in resolution of her jaundice and improvement of her liver function tests.
\end{abstract}

Key Words: Methimazole, Cholestasis, Jaundice, Drug induced liver injury

\section{INTRODUCTION}

Methimazole (MMI) is a commonly used medication in the treatment of hyperthyroidism. Methimazole works by reducing the production of thyroid hormone through inhibition of the enzyme thyroid peroxidase (see Figure 1) ${ }^{[1]}$ This results in decreased synthesis of the thyroid hormones thyroxine and triiodothyronine. It does not, however, eliminate thyroid hormone that was produced prior to the initiation of MMI that is stored in the thyroid or blood. ${ }^{[1]}$ The side effect profile of the antithyroid medications includes cutaneous reactions, gastrointestinal discomfort, agranulocytosis, and hepatic dysfunction. ${ }^{[2]}$ Both Propylthiouracil (PTU) and MMI have been shown to cause elevations in liver transaminases, generally within the first few months of use. ${ }^{[3,4]}$ Hepatic dysfunction, damage, and failure is thought to be more prevalent and severe among users of PTU than MMI, though there is more recent evidence that the profile of hepatotoxicity between users of PTU and MMI is similar. ${ }^{[2,4-6]}$ Women constitute a majority of the reported cases of antithyroid associated liver injury, though this may be due to the higher prevalence of hyperthyroidism and use of antithyroid medications among women. ${ }^{[7,8]}$ PTU associated liver toxicity is thought to occur more commonly among pediatric patients, unlike MMI which more commonly affects patients over 40 years. ${ }^{[9-11]}$ In pregnant patients, MMI is avoided in the first trimester of pregnancy because it has been associated with a higher rate of birth defects than PTU. ${ }^{[12]}$ Whereas, reports of MMI induced hepatic failure and death are extremely rare, there

\footnotetext{
* Correspondence: Kevin C. Kohm; Email: kk799@rwjms.rutgers.edu; Address: Rutgers Robert Wood Johnson Medical School, New Brunswick, United States. 
are a number of cases of PTU induced hepatotoxicity neces- hyperthyroidism is not well characterized, as there are only sitating liver transplant and death associated with the use of PTU in the treatment of hyperthyroidism. ${ }^{[5,13]}$ The association between MMI induced liver toxicity in the treatment of about 30 reported cases in the literature. In this case report, we present a middle-aged woman who developed hepatotoxicity following MMI treatment for Graves’ orbitopathy.

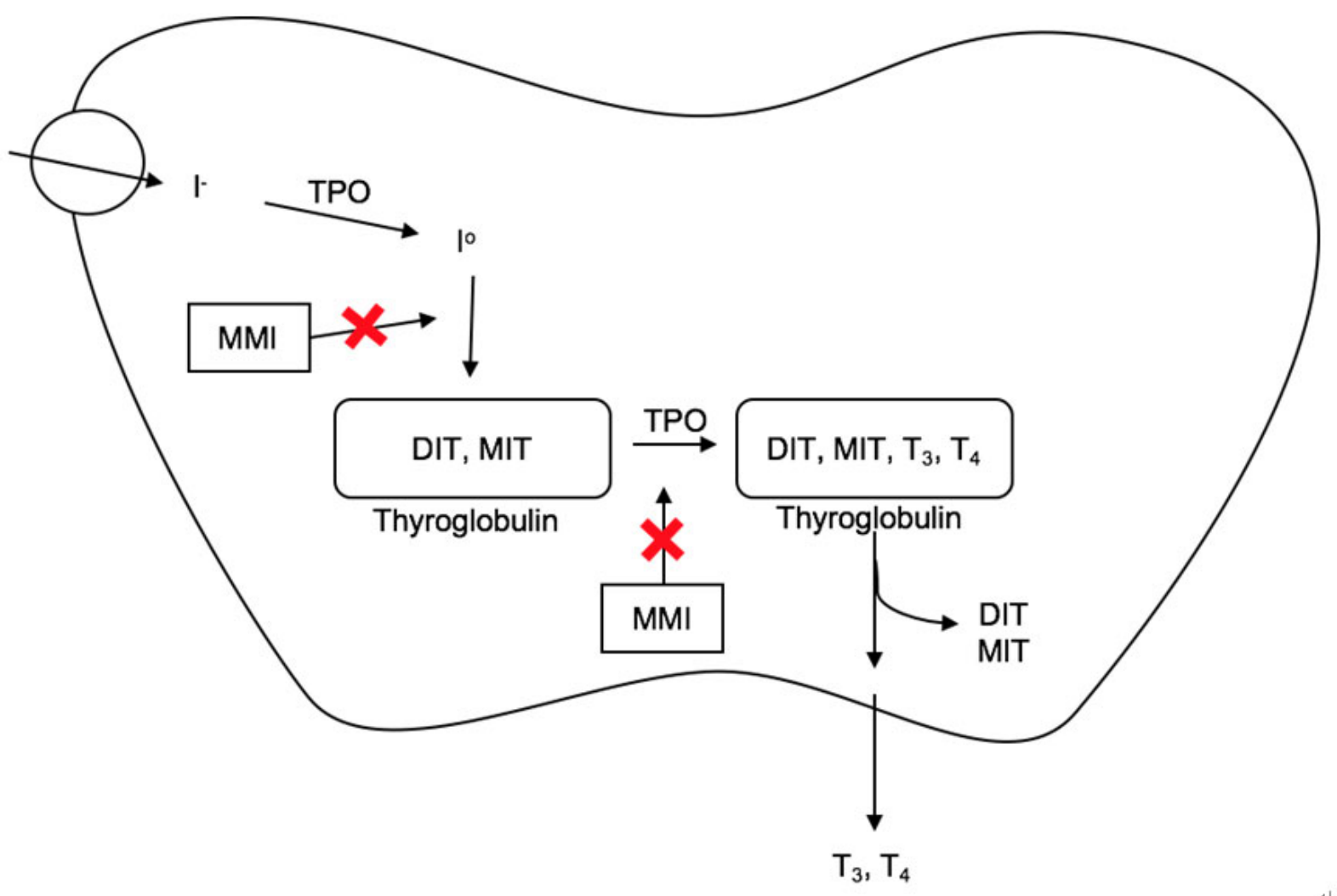

Figure 1. Overview of the mechanism of Methimazole (MMI). MMI blocks production of thyroid hormone (T3, T4) through inhibition of thyroid peroxidase (TPO) and prevention interaction of iodine (Io) with thyroglobulin after it is converted from iodide (I-). Diiodotyrosine (DIT) and monoiodotyrosine (MIT) are not directly affected by MMI.

Table 1. Liver function tests from the day of admission to hospital followed over the next 28 days

\begin{tabular}{|c|c|c|c|c|c|c|c|}
\hline & $\begin{array}{l}\text { Day } \\
1\end{array}$ & $\begin{array}{l}\text { Day } \\
3\end{array}$ & $\begin{array}{c}\text { Day } \\
5\end{array}$ & $\begin{array}{l}\text { Day } \\
7\end{array}$ & $\begin{array}{l}\text { Day } \\
9\end{array}$ & $\begin{array}{l}\text { Day } \\
14\end{array}$ & $\begin{array}{l}\text { Day } \\
28\end{array}$ \\
\hline AST & 853 & 1,038 & 729 & 342 & 191 & 66 & 68 \\
\hline ALT & 1,366 & 1,691 & 1,694 & 1,156 & 799 & 340 & 196 \\
\hline ALP & 954 & 1,133 & 1,173 & 970 & 777 & 466 & 289 \\
\hline TBili & 26.2 & 33.2 & 34.6 & 25.5 & 13.8 & 7.6 & 3.6 \\
\hline
\end{tabular}

Note. Aspartate aminotransferase (AST) (IU/L), Alanine aminotransferase (ALT) (IU/L), Alkaline phosphatase (ALP) (IU/L), Total bilirubin (TBili) (mg/dl)

\section{CASE PResentation}

The patient is a 51-year-old woman with past medical history of Hashimoto's disease complicated by Graves' orbitopathy who presented with new onset painless jaundice. Six weeks prior to presentation she had been started on MMI for treatment of her Graves' orbitopathy. She had previously undergone orbital decompression surgery and treatment with steroids in an attempt to improve her Graves' orbitopathy which were unsuccessful. She had no history of alcohol abuse. On admission to the hospital, her skin exam was notable for jaundice and her abdomen was nontender to palpation. She had no bruises, rashes, spider angiomata, or asterixis. Laboratory studies showed alanine aminotransferase (ALT) $1366 \mathrm{IU} / \mathrm{L}$, aspartate aminotransferase (AST) $853 \mathrm{IU} / \mathrm{L}$, total bilirubin $26.2 \mathrm{mg} / \mathrm{dL}$, alkaline phosphatase $954 \mathrm{IU} / \mathrm{L}$, and albumin $3.4 \mathrm{~g} / \mathrm{dL}$ (see Table 1). Her complete blood count and coagulation profile were within normal limits. A structural cause of her new onset liver disease was ruled out with computed tomography (CT) of her abdomen which showed a normal-appearing liver. Additional imaging for structural cause of her liver disease with magnetic resonance cholangiopancreatography revealed normal biliary tree anatomy without obstruction. Serologic workup for additional causes of liver disease secondary to viral hepatitis, autoimmune hepatitis, primary biliary cholangitis, alpha-1 antitrypsin deficiency, and Wilson's disease were unremark- 
able. The basic metabolic profile (BMP) found that the patient was hyponatremic with a sodium of $131 \mathrm{mmol} / \mathrm{L}$. She was also found to have a total cholesterol level of 793 $\mathrm{mg} / \mathrm{dl}$. Though the patient reported a slight increase in free water intake, her hyponatremia workup including urine studies was negative. Therefore, we believed the etiology of her hyponatremia to be a pseudohyponatremia secondary to hypercholesterolemia. After ruling out structural and serologic causes for liver disease, the patient's jaundice and elevated LFTs were attributed to a drug-induced liver injury secondary to new onset MMI use. MMI was held throughout her hospitalization and she was started on ursodiol $300 \mathrm{mg}$ twice daily. LFTs peaked between days 3 and 5 of hospitalization with ALT 1,847 IU/L, AST 1,028 IU/L, alkaline phosphatase $1,173 \mathrm{IU} / \mathrm{L}$, and total bilirubin $34.6 \mathrm{mg} / \mathrm{dl}$. Upon discharge one week later, LFTs showed significant improvement with ALT 340 IU/L, AST 66 IU/L, alkaline phosphatase 466 IU/L, and total bilirubin $7.6 \mathrm{mg} / \mathrm{dL}$. Hepatic synthetic function remained intact and the patient remained without symptoms through follow-up 28 days after her initial presentation.

\section{DISCUSSION}

The antithyroid medication MMI is frequently prescribed to patients with hyperthyroidism. It is generally well tolerated with a low incidence of associated side effects. ${ }^{[2]} \mathrm{MMI}$ associated liver injury is an especially rare complication. Previous case reports involving MMI associated hepatotoxicity suggest MMI causes damage through a cholestatic process. ${ }^{[14-18]}$ However, in the case presented, the total bilirubin and transaminase (ALT/AST) levels were elevated to a higher degree than those reported in other cases. Though the mechanism for MMI induced hepatotoxicity is not well understood, it is likely the result of several components which would explain the mixed pattern of liver injury seen in the patient described. The first is the metabolism of MMI in the hepatic cytochrome $\mathrm{P} 450$ system, which results in the production of reactive metabolites capable of causing intracellular damage to hepatocytes. ${ }^{[19]} \mathrm{MMI}$ associated liver injury is also believed to contribute to a disruption in bile flow, which would lead to a conjugated hyperbilirubinemia. ${ }^{[20]}$ Lastly, there is some evidence that intracellular damage accumulated within hepatocytes caused by MMI may induce cellular death through apoptosis and/or necrosis. ${ }^{[21,22]}$ A combination of these events in the patient described could have contributed to the onset of her liver injury and would explain the elevation in both her total bilirubin and AST/ALT. This patient's presentation of painless jaundice with elevated bilirubin, AST, and ALT six weeks after initiating MMI and the rapid improvement of her LFTs following the discontinuation of MMI suggests MMI was the cause of her

Published by Sciedu Press liver injury. MMI induced liver toxicity may occur any time from the first few days of treatment through six months after initiation of the drug, though most cases of MMI induced liver injury have been shown to occur within 12-weeks of initiation of the drug. ${ }^{[4,23-26]}$ On her initial presentation six weeks after starting MMI, this patient's ALT was 1366 IU/L (0-35 IU/L), alkaline phosphatase 954 IU/L (30-120 IU/L), and total bilirubin $26.2 \mathrm{mg} / \mathrm{dl}(0.3-1.0 \mathrm{mg} / \mathrm{dl})$, all of which were many folds higher than the upper limit of normal. As the diagnosis of acute drug-induced liver injury is one of exclusion, it was imperative to evaluate and exclude other potential causes of liver injury in this patient who had no previous history of liver disease. Potential causes of liver injury which were evaluated and ruled out in this patient were alcoholism, biliary obstruction, viral hepatitis, autoimmune hepatitis, primary biliary cholangitis, alpha-1 antitrypsin deficiency, and Wilson's Disease. In addition to eliminating other potential causes and establishing a temporal relationship between initiation of medication and onset of liver injury, the diagnosis of acute drug induced liver injury requires any one of a greater than or equal to five-fold increase over the upper limit of normal for ALT, a greater than or equal to two-fold increase over the upper limit of normal for alkaline phosphatase, or a greater than or equal to three-fold increase over the upper limit for ALT with a simultaneous greater than 2-fold increase in bilirubin over the upper limit of normal. ${ }^{[27]}$ This association between MMI initiation and liver injury is confirmed using the Roussel Uclaf Causality Assessment Method (RUCAM), a validated tool which can establish causality between medication use and onset of liver injury. ${ }^{[28]}$ Though the RUCAM scale has been used to demonstrate MMI induced liver injury, in previously reported cases patients were on multiple potentially hepatotoxic drugs which could have clouded the effect of MMI on liver injury, unlike the presented case in which the patient was only taking MMI. ${ }^{[29]}$ The patient's score of 7 on the RUCAM scale indicates MMI is probable cause of her drug induced liver injury. ${ }^{[28]}$ Additionally, the patient was found to be hyponatremic with sodium $131 \mathrm{mmol} / \mathrm{L}$. Hyponatremia workup demonstrated total serum lipids of $793 \mathrm{mg} / \mathrm{dl}$. Using the formula Corrected sodium $(\mathrm{mmol} / \mathrm{L})=$ Measured sodium $(\mathrm{mmol} / \mathrm{L})+[$ total lipids $(\mathrm{mmol} / \mathrm{L}) / 10]$, after converting total serum lipids to $\mathrm{mmol} / \mathrm{L}$, corrected sodium was calculated to be $133 \mathrm{mmol} / \mathrm{L} .{ }^{[30,31]}$ Despite the patient's admitted increase in free water intake prior to presentation, hyponatremia on presentation was likely a pseudohyponatremia secondary to hyperlipidemia. The initiation of MMI and onset of jaundice in a patient found to have elevated liver function tests and hyperlipidemia indicates a cholestatic pattern of acute liver injury secondary to recent MMI use. Fortunately, the 
drug induced liver injury caused by MMI is typically reversible. Aside from immediate discontinuation of the medication, monitoring of liver function tests, and change to an alternative antithyroid treatment, there is no standard therapy shown to affect resolution of MMI induced liver injury, though several approaches have been tried. MMI induced liver injury has been treated in individual cases with steroids, intravascular glutathione, and ursodeoxycholic acid, to varying degrees of success. ${ }^{[15,16,32,33]}$ In the patient described, MMI was immediately discontinued upon her presentation to the hospital, and she was started on ursodiol, which she continued during her one-week hospital stay. During that time, her LFTs were trended, and at the time of discharge one week later her LFTs improved to ALT $340 \mathrm{IU} / \mathrm{L}$, AST $66 \mathrm{IU} / \mathrm{L}$, alkaline phosphatase $466 \mathrm{IU} / \mathrm{L}$, and total bilirubin $7.6 \mathrm{mg} / \mathrm{dl}$. The mainstays of treatment of hyperthyroidism secondary to Graves' disease are antithyroid medications, radioactive iodine ablation, and thyroidectomy.[34] Because

\section{REFERENCES}

[1] Truven Health Analytics. DynaMed Plus [Internet]. Ipswich (MA): EBSCO Information Services. 1995-. Record No. 356448, Methimazole.

[2] Cooper DS. The side effects of antithyroid drugs. The Endocrinologist. 1999; 9: 457-478. https ://doi.org/10.1097/00019616 -199911000-00008

[3] Nakamura H, Noh JY, Itoh K, et al. Comparison of methimazole and propylthiouracil in patients with hyperthyroidism caused by Graves' disease. J Clin Endocrinol Metab. 2007; 92(6): 2157-2162. PMid:17389704. https://doi.org/10.1210/jc.2006-2135

[4] Yang J, Li LF, Xu Q, et al. Analysis of 90 cases of antithyroid druginduced severe hepatotoxicity over 13 years in China. Thyroid. 2015; 25(3): 278-83. PMid:25384184. https ://doi.org/10.1089/th y. 2014.0350

[5] Williams KV, Nayak S, Becker D, et al. Fifty years of experience with propylthiouracil-associated hepatotoxicity: what have we learned? J Clin Endocrinol Metab 1997; 82(6): 1727-1733. PMid:9177371. https://doi.org/10.1210/jcem.82.6.4011

[6] Carrion AF, Czul F, Arosemena LR, et al. Propylthiouracil-induced acute liver failure: role of liver transplantation. Int $\mathrm{J}$ Endocrinol. 2010; 2010: 910636. PMid:21234410. https ://dx.doi.org/10. $1155 / 2010 / 910636$

[7] Hollowell JG, Staehling NW, Flanders WD, et al. Serum TSH, T(4), and thyroid antibodies in the United States population (1988 to 1994): National Health and Nutrition Examination Survey (NHANES III). J Clin Endocrinol Metab. 2002;87:489-499. PMid:11836274. https://doi.org/10.1210/jcem.87.2.8182

[8] Whitacre CC. Sex differences in autoimmune disease. Nat Immunol 2001; 2(9): 777-780. PMid:11526384. https://doi.org/10.103 8/ni0901-777

[9] Rivkees SA. Pediatric Graves' disease: controversies in management. Horm Res Paediatr. 2010; 74(5): 305-311. PMid:20924158. https://doi.org/10.1159/000320028
PTU is also strongly associated with hepatic injury, this patient was advised to follow with her primary care provider and endocrinologist following discharge from the hospital for treatment of her hyperthyroidism. ${ }^{[34]}$

\section{Conclusion}

The ability to identify uncommon medication side is a difficult task for the clinician especially when symptoms may not present until months after medication initiation. Failure to recognize MMI induced liver injury as a potential cause of liver disease may lead to serious hepatic dysfunction. We hope to draw attention to the association between initiation of MMI and acute drug induced liver injury, and hope that clinicians will remain mindful of this rare but serious side effect when using this medication in the treatment of hyperthyroidism.

\section{CONFlicts of InTEREST Disclosure}

The authors have declared no conflicts of interest.
[10] Cooper DS, Rivkees SA. Putting propylthiouracil in perspective. J Clin Endocrinol Metab. 2009; 94(6): 1881-1882. PMid:19401361. https://doi.org/10.1210/jc.2009-0850

[11] Rivkees S, Szarfman A. Dissimilar hepatotoxicity profiles of propy1thiouracil and methimazole in children. J Clin Endocrinol Metab 2010; 95(7): 3260-3267. PMid:20427502. https ://doi .org/10 $.1210 /$ jc. 2009-2546

[12] Andersen S, Olsen J, Wu CS, et al. Birth defects after early pregnancy use of antithyroid drugs: a Danish nationwide study. J Clin Endocrinol Metab. 2013; 98(11): 4373-4378. PMid:24151287. https://doi.org/10.1210/jc. 2013-2831

[13] Russo M, Galanko JA, Shrestha R, et al. Liver transplantation for acute liver failure from drug induced liver injury in the United States. Liver Transpl 2004; 10(8): 1018-1023. PMid:15390328. https://doi.org/10.1002/1t.20204

[14] Zou H, Jin L, Wang LR, et al. Methimazole-induced cholestatic hepatitis: two cases report and literature review. Oncotarget. 2016; 7(4): 5088-5091. https://doi.org/10.18632/oncotarget. 6144

[15] Zhang M, Zhou H, He R, et al. Steroids for the treatment of methimazole-induced severe cholestatic jaundice in a 74-yearold woman with type 2 diabetes. Endocrine. 2010; 37(2): 241243. PMid:20960257. https ://doi .org/10.1007/s12020-009 $-9305-9$

[16] Gallelli L, Staltari O, Palleria C, et al. Hepatotoxicity induced by methimazole in a previously healthy patient. Curr Drug Saf. 2009; 4(3): 204-206. PMid:19534646. https : //doi .org/10.2174/15 7488609789006912

[17] Hung YT, Yu WK, Chow E. Delayed cholestatic hepatitis due to methimazole. Hong Kong Med J. 1999 Jun; 5(2): 200-201.

[18] Ramos-Bonner LS, Goldberg TH, Moyer S, et al. Methimazoleinduced cholestatic jaundice in an elderly hyperthyroid patient. Am J Geriatr Pharmacother. 2007; 5(3): 236-240. PMid:17996663. https ://doi.org/10.1016/j.amjopharm.2007.10.003 
[19] Heidari R, Niknahad H, Jamshidzadeh A, et al. Factors affecting drug-induced liver injury: antithyroid drugs as instances. Clin Mol Hepatol. 2014; 20(3): 237-248. PMid:25320726. https ://doi .or $\mathrm{g} / 10.3350 / \mathrm{cmh} .2014 .20 \cdot 3.237$

[20] Trauner M, Meier PJ, Boyer JL. Molecular pathogenesis of cholestasis. N Engl J Med. 1998; 339: 1217-1227. PMid:9780343. https : //doi.org/10.1056/NEJM199810223391707

[21] Reed JC. Apoptosis-regulating proteins as targets for drug discovery. Trends Mol Med 2001; 7: 314-319. https ://doi.org/10.1016/ S1471-4914(01) 02026-3

[22] Pessayre D, Berson A, Fromenty B, et al. Mitochondria in steatohepatitis. Semin Liver Dis 2001; 21: 57-69. PMid:11296697. https: //doi.org/10.1055/s-2001-12929

[23] Wang MT, Lee WJ, Huang TY, et al. Antithyroid drug-related hepatotoxicity in hyperthyroidism patients: a population-based cohort study. Br J Clin Pharmacol. 2014; 78(3): 619-629. PMid:25279406. https://doi.org/10.1111/bcp.12336

[24] Woeber KA. Methimazole-induced hepatotoxicity. Endocrine Practice. 2002; 8: 222-224. PMid:12467281. https ://doi .org/10.4 158/EP.8.3.222

[25] Cooper DS. Antithyroid drugs. N Engl J Med. 2005; 352: 905-917. PMid:15745981. https : //doi.org/10.1056/NEJMra042972

[26] Licata A. Adverse drug reactions and organ damage: The liver. Eur J Intern Med. 2016; 28: 9-16. PMid:26827101. https ://doi.org/ 10.1016/j.ejim.2015.12.017

[27] Aithal GP, Watkins PB, Andrade RJ, et al. Case definition and phenotype standardization in drug-induced liver injury. Clin Pharmacol
Ther. 2011; 89(6): 806-815. PMid:21544079. https://doi.org/ 10.1038/clpt. 2011.58

[28] Danan G, Teschke R. RUCAM in Drug and Herb Induced Liver Injury: The Update. Int J Mol Sci. 2015; 17(1). PMid:26712744. https://doi.org/10.3390/ijms17010014

[29] Ji H, Yue F, Song J, Zhou X. A rare case of methimazole-induced cholestatic jaundice in an elderly man of Asian ethnicity with hyperthyroidism: A case report. Medicine (Baltimore). 2017; 96(49): e9093. PMid:29245333. https ://doi .org/10.1097/MD.00000 00000009093

[30] Dimeski G, Mollee P, Carter A. Effects of hyperlipidemia on plasma sodium, potassium, and chloride measurements by an indirect ionselective electrode measuring system. Clin Chem. 2006; 52(1): 155156. PMid:16391336. https://doi.org/10.1373/clinchem. 2 005.054981

[31] Adashek ML, Clark BW, Sperati CJ, et al. The Hyperlipidemia Effect: Pseudohyponatremia in Pancreatic Cancer. Am J Med. 2017; 130(12): 1372-1375. PMid:28882662. https://doi.org/10.101 6/j.amjmed.2017.08.018

[32] Yang J, Zhong J, Zhou LZ, et al. Sudden onset agranulocytosis and hepatotoxicity after taking methimazole. Intern Med. 2012; 51: 2189-2192. PMid:22892501. https://doi.org/10.2169/inte rnalmedicine.51.7845

[33] Lee SO, Choi JK, Kim HS, et al. A case of similar pattern of hepatotoxicity after propylthiouracil and methimazole. Korean J Hepatol 1999; 5: 136-141.

[34] De Leo S, Lee SY, Braverman LE. Hyperthyroidism. Lancet. 2016; 388(10047): 906-918. https://doi.org/10.1016/S0140-673 $6(16) 00278-6$ 